\title{
When is a multidisciplinary surgical approach required in sinonasal tumours with cranial involvement?
}

\author{
Quando è indicato un approccio chirurgico multidisciplinare nei tumori naso-sinusali \\ con estensione cranica?
}

\author{
Marco Ferrari ${ }^{1,2,3}$, Diego Cazzador $^{1}$, Stefano Taboni ${ }^{1,3,4}{ }^{\text {, Maria Vittoria Trimarchi }}{ }^{1}$, Enzo Emanuelli ${ }^{1}$, Piero Nicolai ${ }^{1}$ \\ ${ }^{1}$ Section of Otorhinolaryngology, Head and Neck Surgery, University of Padua, "Azienda Ospedaliera di Padova", Padua, Italy; \\ ${ }^{2}$ Technology for Health (PhD program), Department of Information Engineering, University of Brescia, Brescia, Italy; ${ }^{3}$ University \\ Health Network (UHN) Guided Therapeutics (GTX) Program International Scholar, UHN, Toronto, Canada; ${ }^{4}$ Artificial Intelligence in \\ Medicine and Innovation in Clinical Research and Methodology (PhD program), Department of Clinical and Experimental Sciences, \\ University of Brescia, Brescia, Italy
}

\begin{abstract}
SUMMARY
The term "sinonasal tumours" includes a large spectrum of diseases, which are characterized by heterogeneous biological behavior and prognosis, and located in a critical anatomic area. Diagnosis and treatment of sinonasal tumours require the contribution of different disciplines. A narrative review was performed to highlight the role of surgeons in contributing to a multidisciplinary approach to sinonasal tumours. Diagnosis and staging of sinonasal tumours is challenging and requires collaboration between surgeons, radiologists, and pathologists. The identification and management of critical extensions (orbital or intracranial encroachment, vascular abutment or encasement) is fundamental for successful treatment. Most cases of advanced sinonasal tumours can undergo surgical intervention by an adequately trained otorhinolaryngological team. The contribution of neurosurgeons and oculoplastic surgeons is required in selected scenarios. In rare circumstances, multidisciplinary reconstructive strategies can be indicated for complex tissue defects. Furthermore, a multidisciplinary approach is pivotal in the management of perioperative complications. While surgery remains the mainstay of treatment, the role of non-surgical adjuvant or even exclusive treatments is constantly expanding.
\end{abstract}

KEY WORDS: sinonasal tumours, anterior skull base tumours, cranial involvement, multidisciplinary team, multidisciplinary treatment

\section{RIASSUNTO}

I tumouri nasosinusali includono un ampio spettro di neoplasie caratterizzate da un comportamento biologico eterogeneo e dalla localizzazione in un distretto anatomico critico. Diverse discipline mediche sono coinvolte nella diagnosi e nel trattamento di tali tumori. Una revisione narrativa della letteratura è stata condotta per identificare i ruoli delle specialità chirurgiche che appartengono al gruppo multidisciplinare. La diagnosi e la stadiazione dei tumori nasosinusali richiede la collaborazione tra chirurghi, radiologi e patologi. L'identificazione delle estensioni tumorali critiche è fondamentale per un corretto trattamento. L'intervento chirurgico necessario per la maggior parte dei tumori nasosinusali avanzati può essere eseguito da un team otorinolaringoiatrico con adeguato training. Il contributo di neurochirurghi e di specialisti in chirurgia orbitaria è necessario in scenari selezionati. Nei casi di difetti chirurgici complessi possono essere necessarie strategie ricostruttive multidisciplinari. La collaborazione chirurgica multidisciplinare è essenziale per la gestione delle complicanze nel periodo perioperatorio. Nonostante la chirurgia rimanga il trattamento principale, si sta affermando una vasta gamma di trattamenti non-chirurgici, adiuvanti o esclusivi.

PAROLE CHIAVE: tumori nasosinusali, tumori della base cranica anteriore, coinvolgimento cranico, gruppo multidisciplinare, trattamento multidisciplinare
Received: October 20, 2020

Accepted: January 15, 2021

\section{Correspodence}

Marco Ferrari

Section of Otorhinolaryngology, Head and Neck Surgery, Department of Neurosciences, University of Padua, "Azienda Ospedaliera di Padova" via Giustiniani 2, 35128 Padua, Italy

E-mail: 1990marcoferrari@gmail.com

Funding

None.

Conflict of interest

The Authors declare no conflict of interest.

How to cite this article: Ferrari M, Cazzador $\mathrm{D}$, Taboni $\mathrm{S}$, et al. When is a multidisciplinary surgical approach required in sinonasal tumours with cranial involvement?Acta Otorhinolaryngol Ital 2021;41(SUPPL.1):S3-S17. https://doi. org/10.14639/0392-100X-suppl.1-41-2021-01

() Società Italiana di Otorinolaringoiatria e Chirurgia Cervico-Facciale

\section{(c) (1) $(2)$}

This is an open access article distributed in accordance with the CC-BY-NC-ND (Creative Commons Attribution-NonCommercial-NoDerivatives 4.0 International) license. The article can be used by giving appropriate credit and mentioning the license, but only for non-commercial purposes and only in the original version. For further information: https:// creativecommons.org/licenses/by-nc-nd/4.0/deed.en 


\section{Introduction}

Ideally, sinonasal tumours should always be managed through a multidisciplinary team (MDT) approach. In fact, while most surgical procedures for advanced sinonasal cancers are performed by a single-specialty surgical team, the path leading patients to the operating theater requires a long list of surgical specialists and non-surgical physicians, whose contribution is variably needed based on the characteristics of each case. The need for multidisciplinary management owes to the vast spectrum of diseases included in the term "sinonasal tumours", which are located in a watershed area where the combined knowledge of different specialties and subspecialties is frequently a must.

The benefit of using MDT approach has been thoroughly and objectively demonstrated for head and neck cancers ${ }^{1}$. The present article aims to highlight the surgical aspects of a modern MDT approach to advanced sinonasal tumours.

Sinonasal cancer frequently represents a challenge due to a number of critical issues, the most relevant being reliability of diagnosis, extension towards the intracranial spaces, face and orbit, possibility to spare content of the orbital cavity, sensitivity to non-surgical treatments, expected treatment-related morbidity, and prognosis. Therefore, sinonasal cancers are frequently at the top of the list of malignancies requiring thorough multidisciplinary assessment. Similarly, some benign or borderline sinonasal diseases that are usually treated by surgery might benefit from a MDT approach in view of some special characteristics they can display. The rarity of sinonasal tumours alongside with the willingness of patients to refer to centers with adequate experience lead most cases to concentrate into "superspecialized" centers. On one hand, this implies that expertise in management of sinonasal tumours cannot prescind from training in those centers where an adequate volume of cases is managed by an MDT. On the other hand, cases diagnosed in centers with a low volume of sinonasal tumours should be cautiously managed and referral to or consultation with institutions with acknowledged experience should be considered as an act of medical responsibility ${ }^{2}$. This is even more true when considering that for the majority of sinonasal tumours the actual chance to cure the patient relies on primary treatment, whereas recurrence is much more difficult to treat irrespective of MDT experience ${ }^{3}$.

The professional figures who should ideally participate in a MDT are summarized in Table I and clustered as "essential" and "required on a case-by-case basis" depending on how often they are consulted according to authors' experience. Though surgeons are frequently the "quarterback" of the MDT approach to sinonasal tumours, different non- surgical physicians alternatively lead case management depending upon the specific phase and circumstances.

\section{Pretreatment diagnosis}

Diagnosis of tumours of the sinonasal tract is a considerable challenge to the pathologist. This is mostly due to the rarity, pathological heterogeneity, and possible morphological similarity of different sinonasal tumours.

An emblematic example is represented by "small round blue cell tumours". This term was coined by Bridge et al. in 2010 and refers to tumours displaying a non-specific morphology, which consists of "monotonous population of undifferentiated tumour cells with relatively small-sized nuclei and scant cytoplasm" ${ }^{4}$. This non-specific morphology is potentially underlaid by a number of cancers including adenoid cystic carcinoma (ACC), Ewing-family tumours, human papilloma virus (HPV)-related, ACC-like carcinoma, non-keratinizing squamous cell carcinoma (SCC), lymphoepithelial carcinoma, NUT carcinoma, SMARCB1/ INI1-deficient carcinoma, sinonasal undifferentiated carcinoma (SNUC), neuroendocrine carcinomas (NEC), mucosal melanoma (MM), olfactory neuroblastoma (ONB), rhabdomyosarcoma, mesenchymal chondrosarcoma, and other tumours ${ }^{5}$. As a consequence, a rational investigation through immunohistochemistry is essential to unveil molecular hints that ultimately lead to correct diagnosis ${ }^{5}$. As for all pathological conundrums, information coming from clinical history as well as endoscopic and radiologic findings can be of help to anticipate a diagnosis or at least estimate its reliability in the pretreatment setting ${ }^{6,7}$.

Another challenge faced by the MDT is that knowledge of sinonasal tumours has been evolving with an accelerating pace ${ }^{8}$. This concept is well exemplified by SNUC histology. Originally described by Frierson et al. in $1986^{9}$, SNUC soon raised the interest of many researchers and clinicians. Since its description, it has represented a diagnosis of exclusion, thus early acquiring the role of "wastebasket entity" which still characterizes SNUC ${ }^{10}$. However, refinements in molecular diagnostics and biological understanding of sinonasal tumours progressively led some cancers initially labelled under the umbrella of SNUC to be diagnosed based on an immunohistochemical identifier rather than by exclusion. SMARCB1/INI1deficient carcinoma ${ }^{11}$, SMARCA4-deficient carcinoma ${ }^{12}$, IDH2-mutant SNUC ${ }^{13}$, HPV-related SNUC ${ }^{14}$, and NUT carcinoma ${ }^{15}$ (formally not considered a SNUC subtype) ${ }^{16}$ are the most relevant examples of this phenomenon. While providing new diagnostic tools, this process should also prompt pathologists and their MDTs to be updated on the constant advancements of diagnosis of sinonasal 
Table I. Members of the multidisciplinary team to treat advanced sinonasal tumours.

\begin{tabular}{|c|c|}
\hline $\begin{array}{l}\text { Multidisciplinary team member } \\
\text { Essential members }\end{array}$ & Role(s) \\
\hline Otorhinolaryngologist, head and neck surgeon & $\begin{array}{l}\text { Clinical diagnosis and pre-treatment biopsy } \\
\text { Surgical excision and skull base reconstruction } \\
\text { Pathologic staging* } \\
\text { Clinical follow-up }\end{array}$ \\
\hline Radiologist, PET-trained physician & $\begin{array}{l}\text { Tumour mapping and re-staging } \\
\text { Pathologic staging* } \\
\text { Radiologic follow-up }\end{array}$ \\
\hline Pathologist & $\begin{array}{l}\text { Preoperative pathologic diagnosis } \\
\text { Postoperative pathologic evaluation of the surgical specimen } \\
\text { Pathologic staging* }\end{array}$ \\
\hline Medical oncologist & $\begin{array}{l}\text { Neoadjuvant chemotherapy } \\
\text { Concomitant chemotherapy } \\
\text { Palliative chemotherapy } \\
\text { Immunotherapy and biotherapy }\end{array}$ \\
\hline Radiation oncologist & $\begin{array}{l}\text { Definitive radiation therapy } \\
\text { Adjuvant radiation therapy } \\
\text { Palliative radiation therapy } \\
\text { Referral to a particle therapy center }\end{array}$ \\
\hline \multicolumn{2}{|l|}{ Required on a case-by-case basis } \\
\hline Neurosurgeon & $\begin{array}{l}\text { Management of cases with critical transcranial and/or orbital apex extension } \\
\text { Bypass surgery } \\
\text { Management of intracranial complications }\end{array}$ \\
\hline Plastic surgeon, surgeon with advanced plastic surgery training & Reconstruction of complex defects \\
\hline Ophthalmologist, oculoplastic surgeon, maxillofacial surgeon & Management of cases with advanced involvement of the orbit and/or lacrimal system \\
\hline Neuroradiologist, interventional radiologist & $\begin{array}{l}\text { Temporary occlusion test } \\
\text { Endovascular occlusion/stenting of the internal carotid artery }\end{array}$ \\
\hline Anesthesiologist, critical care physician & $\begin{array}{l}\text { To anticipate complex cases from an anesthesiologic standpoint } \\
\text { To support management of intraoperative and early postoperative complications } \\
\text { To minimize early postoperative events potentially favoring failure of the skull base } \\
\text { reconstruction (e.g. nausea, vomit, cough) }\end{array}$ \\
\hline Dentist/oral health consultant & $\begin{array}{l}\text { To address dental/periodontal disease before radiation therapy } \\
\text { Dental rehabilitation in patients who undergo midfacial bone reconstruction }\end{array}$ \\
\hline Psychiatrist, psychologist, mental health professional & To diagnose and address mental health disorders \\
\hline Pediatrician, pediatric subspecialist(s) & $\begin{array}{l}\text { To anticipate and manage age-related medical/surgical issues in pediatric patients } \\
\text { To lead management of complex cases in syndromic patients } \\
\text { To propose and manage complementary antiangiogenic and other medical therapies }\end{array}$ \\
\hline Geriatrician & To anticipate and manage age-related medical/surgical issues in elderlies \\
\hline Endocrinologist & To anticipate and manage surgery- and/or disease-related endocrinological disorders \\
\hline Hematologist & To lead management of lymphoproliferative disorders \\
\hline Palliative medicine physician, pain management specialist & To lead management of patients for whom palliation is indicated \\
\hline Thoracic surgeon and other surgeons & To perform metastasectomy in carefully selected patients \\
\hline Prosthetic anaplastologist & To organize facial/orbital/nasal/palatal prosthetic rehabilitation \\
\hline Hyperbaric medicine physician & $\begin{array}{l}\text { To indicate and organize hyperbaric oxygen therapy in patients with skull base } \\
\text { radionecrosis, osteomyelitis, or similar disorders }\end{array}$ \\
\hline
\end{tabular}

* Pathologic staging is best performed in consensus between the pathologist, radiologist, and surgeon who performed the resection.

tumours and equip them with the most modern and promising staining methods.

Despite improvement in the understanding and definition of sinonasal tumours, diagnosis remains a challenge, as witnessed by the considerable rate of misdiagnoses observed even in referral centers. Mehrad et al. analyzed 500 consecutive cases of head and neck tumours and found 20 (4.0\%) had major diagnostic discrepancies (with "major" denoting a "significant change in patient management and/or prognosis"), 4 (20.0\%) of which were sinonasal tumours ${ }^{17}$. 
Considering the prevalence of sinonasal tumours in their series, the sinonasal tract was the site with the highest rate of major diagnostic discrepancies (19.0\% vs 0.0-8.3\%). Schreiber et al. reported on a series of 77 nasoethmoidal tumours on which they analyzed diagnostic reliability of pretreatment biopsy ${ }^{7}$. They found that the overall reliability was $83.1 \%$, with pretreatment diagnosis of SCC or miscellaneous tumours (i.e. "malignant neoplasm", "mesenchymal neoplasm", "poorly differentiated carcinoma", "undifferentiated carcinoma not otherwise specified", and NEC) and sampling of a small volume of tissue being significantly associated with the highest risk of misdiagnosis. On the other hand, diagnosis of adenocarcinoma, MM, and ONB was associated with high reliability (97-100\%), which led the authors to conclude that well-defined clinical scenarios such as, respectively, wood or leather workers, elderly with pigmented sinonasal lesions, and lesions centered in the olfactory cleft with a cystic component on the intracranial aspect could be reasonably sampled in the outpatient clinic under local anesthesia. Other presentations should warrant ample sampling (i.e. at least $2 \mathrm{~mL}$ ), which is best achieved under sedation or even general anesthesia. Similarly, Ganti et al. described 11/52 (21.2\%) cases of discrepancy between preoperative and postoperative histopathology over a 4-year time span ${ }^{18}$. In particular, they distinguished 4 (7.7\%) cases of shift from benign to borderline/malignant disease, $3(5.8 \%)$ from a malignancy to another cancer with more aggressive behavior, and $4(7.7 \%)$ from malignancy to a benign disease.

These data dispel doubts that pathologists should be an active member of MDTs treating sinonasal tumours. Not only is the pathologist in charge of providing pretreatment diagnosis, but also in sharing its estimated reliability, potential pitfalls, and most probable alternative diagnoses with the MDT. As a final remark, the pathologist is also involved in other essential phases of the diagnostic-therapeutic process, which includes postoperative diagnosis, detection of pathological risk factors, and pathological staging. In this regard, it is the authors' opinion that definition of margin status and pathological staging should be the result of a teamwork from the MDT. In fact, both these processes require in-depth anatomical mapping of tumour extension, which cannot ignore a simultaneous analysis of imaging and consultation with the surgeons who performed surgery.

\section{Mapping of local extension of the tumour through pretreatment imaging}

Improvement of cross-sectional imaging, with special reference to magnetic resonance (MRI), has been one of the main evolutionary drivers in the field of sinonasal tumours.

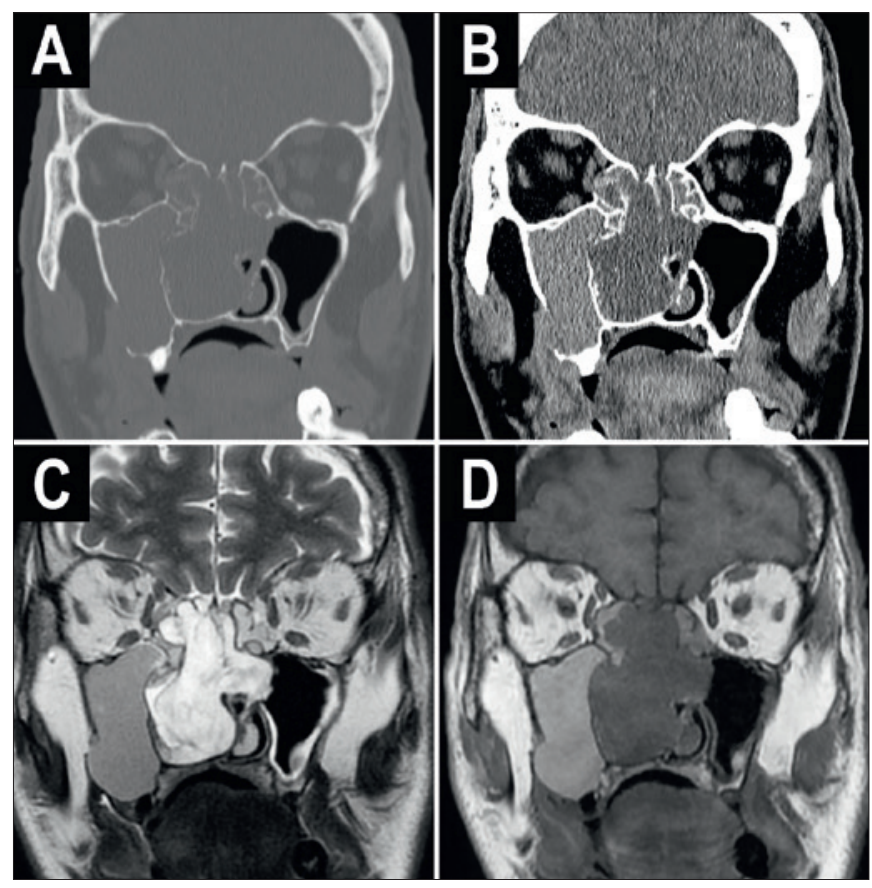

Figure 1. Computed tomography (A, B) and magnetic resonance imaging (C, D) of a mucinous, signet-ring cell, intestinal-type adenocarcinoma of the right nasoethmoidal complex. Different imaging modalities allow depiction of tumour extension with respect to the most relevant adjacent compartments (i.e. orbital cavity, skull base).

Precise mapping of tumour extension is a pivotal step in treatment planning, particularly in relation to orbit and skull base invasion (Fig. 1). The presence in the MDT of a head and neck radiologist with specific expertise in sinonasal tumours is therefore crucial ${ }^{19}$.

Nasal cavity and paranasal sinuses are separated from the orbit and the intracranial space by several bony laminae, which are thought to serve as barrier against tumour spread. Computed tomography (CT) depicts changes and losses of mineralization of bony structures ${ }^{20,21}$. However, resorption of the mineral content of a bony wall does not necessarily imply that the tumour has invaded the adjacent compartment. In fact, the most effective barrier to neoplastic spread beyond sinonasal boundaries is known to be the periosteum ${ }^{22}$. Therefore, knowledge of infiltration and/or transgression of the periosteum represents a critical information for therapeutic planning. In this regard, MRI has an intrinsic advantage over CT. In fact, the cortical bone and periosteum can be adequately demonstrated as a single, homogeneous hypointense layer, irrespective of bone mineralization ${ }^{23}$. Similarly, the dura and bony skull base appear as a single hypointense layer in non-contrast-enhanced sequences. The dura differs from extracranial periosteum because it frequently reacts to an advancing lesion by signifi- 
cantly increasing its thickness and enhancement ${ }^{24}$. Overall, the biological heterogeneity of sinonasal tumours translates into 4 different patterns of bone involvement ${ }^{25}: 1$ ) bone remodeling, with displacement and thinning of bony walls ${ }^{26}$; 2) cortical destruction, with interruption of the cortical bone layer; 3) permeative invasion, which is replacement of medullary bone in the absence of obvious cortical interruption; 4) medullary sclerosis, with fibrous-like tissue formation in the medullary portion of a bone structure.

Once bony boundaries are transgressed, accurate description of the stage of involvement of adjacent compartments becomes paramount. In fact, infiltration of adjacent compartments such as the orbit, soft tissues of the face, and intracranial space might dictate the need for neoadjuvant treatment, the response to which cannot be adequately evaluated unless the initial extension has been accurately staged.

Maroldi et al. demonstrated that MRI is superior to CT in predicting the absence of orbital invasion (negative predictive value: $100 \%$ vs $75 \%$, overall accuracy $96 \%$ vs $81 \%$, respectively) ${ }^{27}$. In a recent study, Ferrari et al. analyzed the diagnostic performance of MRI in detecting the involvement of single orbital structures: the adjusted diagnostic accuracy was satisfactory $(\geq 80.0 \%)$ for the bony layer, extraconal fat, and muscular layer, but suboptimal $(<80.0 \%)$ for the periorbit and intraconal compartment ${ }^{28}$. Overall, MRI was confirmed to provide precious preoperative information on orbit involvement, though with specific shortcomings the MDT should be aware of. Another goal of imaging is to establish the depth of transcranial invasion ${ }^{29,30}$. Different degrees of invasion through the anterior skull base can be identified by analyzing the signal of dura, cerebrospinal fluid (CSF), brain, and tumour, which is best depicted by MRI ${ }^{25}$. Finally, potential contraindications to surgery such as encasement of internal carotid artery and involvement of the cavernous sinus should be evaluated on preoperative imaging.

In order to facilitate comprehensive radiologic evaluation of sinonasal tumours, Maroldi et al. proposed a checklist approach $\left.{ }^{19}: 1\right)$ the first step consists of separating the tu- mour from the signal of retained mucus or inflamed thickened mucosa; 2) the second step is mapping gross tumour extension: once the epicenter of tumour is located, its 3-dimensional extent should be analyzed systematically including six "vectors of growth" (i.e. anterior, posterior, medial, lateral, caudal, cranial); 3) the last step is inference of potential patterns of non-macroscopic spread based on imaging findings (e.g. enhancement, signal replacement) and clinical information (e.g. histology, primary versus recurrent presentation). The same authors suggested that the radiologist joining the MDT should carry "hand luggage" with 4 epistemic compartments ${ }^{19}$ : mastering of technical solutions, knowledge of radiologic anatomy, understanding of information with practical implications for other MDT members, and awareness of different biological behaviors displayed by tumours of the sinonasal tract.

\section{Preoperative embolization and preventive measures against major vascular complications}

Resection of sinonasal tumours with a critical relationship to major vessels and/or intrinsic hypervascularity (Tab. II) represents a challenge ${ }^{31}$. In fact, uncontrolled bleeding causes poor visualization, increases the risk of complications such as cranial nerve injury, CSF leak, and rupture of major vessels, and limits the ability to completely remove the tumour. Potential additional morbidity includes postoperative anemia and blood transfusion-related issues. Even if immediate corrective protocols are available, death is also a possible consequence of unresolved massive intraoperative blood loss ${ }^{32}$. Consequently, all sinonasal tumours displaying hypervascularity and/or abutting or encasing a major vessel should be discussed with and possibly managed by an MDT including an interventional radiologist.

\section{Angiography and embolization}

Blood supply to the tumour can be surmised based on the location and extent of the lesion. This particularly applies

Table II. Most common hypervascularized tumours of the sinonasal tract.

Juvenile angiofibroma

Hemangioma (lobular capillary hemangioma)

Angioleiomyoma

Sinonasal paraganglioma

Vascular malformations

Borderline/low grade malignant tumour

Primary malignant vascular tumours

Secondary hypervascularized tumours
Venous malformation (cavernous hemangioma)

Glomangiopericytoma

Solitary fibrous tumour

Angiosarcoma

Renal cell carcinoma 
to juvenile angiofibroma (JA), which predominantly receives vascular supply from the external carotid artery but can also be fed by branches arising from the internal carotid artery (ICA), especially in case of large lesions. Notably, $30 \%$ of JAs show a bilateral vascular supply, which increases to almost $70 \%$ in advanced cases ${ }^{33}$. Vascular feeders of sinonasal paragangliomas ${ }^{34}$, hemangiopericytomas ${ }^{35}$, haemangiomas ${ }^{36}$, and other hypervascularized lesions ${ }^{37,38}$ are less well known given their rarity. Transarterial angiography provides the MDT with a case-specific map of vascular feeders, which enables estimation of intraoperative risks, morbidity of embolization or ligation, and potential residual vascularity following embolization.

Embolization is meant to reduce tumour vascularity through the injection of particles, coils, liquid embolic agents, or other substances. It can be performed through direct puncture of the tumour and/or via an endovascular approach. Traditionally, tumour embolization has been achieved via a transarterial route (most commonly through the femoral artery) with superselective catheterization and embolization of feeding vessels. Superselective catheterization of external carotid branches not only depicts the vascular architecture of the lesion, but also unveils potentially dangerous anastomoses with the cerebral/orbital vasculature which can result in subtotal embolization or even dramatic complications such optic nerve ischemia ${ }^{39}$. Evaluation of the contralateral carotid branches should be done to exclude contribution to tumour blush, particularly when the tumour extends beyond the midline ${ }^{40}$. Direct puncture techniques using liquid embolic agents (e.g. Onyx) have also been described. They can be used in conjunction with transarterial embolization or as a sole modality of embolization ${ }^{41}$.

Timing is a crucial aspect of embolization. Therefore, coordination of different members of the MDT is essential to guarantee a satisfactory result. Early resection following embolization (i.e. within 24 hours) may obscure the benefits of the procedure by not allowing enough time for tumour devascularization to occur; on the other hand, waiting too long following embolization can lead to tumour revascularization or even dramatic consequences such as tumour inflammation, infarction, and/or swelling. For these reasons, surgery should not be delayed beyond 48-72 hours following embolization ${ }^{33,40,42,43}$. However, a complex case of JA treated with staged surgery performed 8 days after trimodal embolization has been reported (Fig. 2) ${ }^{44}$.

\section{Measures against major vascular complications}

While the indications and contraindications to surgery for sinonasal tumours have considerably evolved throughout the last decades, abutment, encasement, and frank invasion of the ICA have been invariably considered as a major

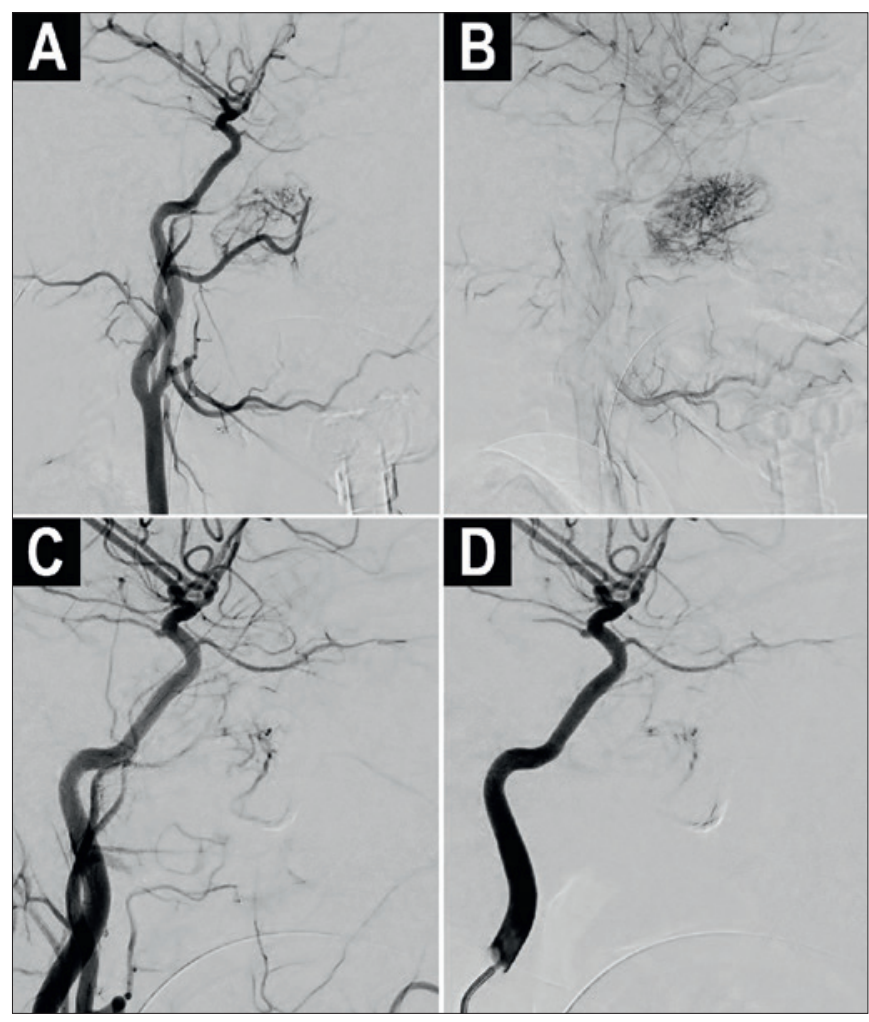

Figure 2. Angiography of a case of right juvenile angiofibroma with feeders coming from both the internal and external carotid artery systems (A, B). Following combined transarterial (with polyvinyl alcohol particles) and translesional (with 0 ny $\mathrm{x}^{\circledR}$ ) embolization of the lesion and transarterial closure of the ipsilateral maxillary artery, only minimal residual enhancement from internal carotid artery feeders can be observed (C, D).

criterion of difficult, dangerous, or even impossible resectability. Intraoperative rupture of the ICA has been reported to occur in $28 / 7160(0.4 \%)$ endoscopic procedures and its consequences ranges from death to non-lethal cerebrovascular events, pseudoaneurysm, carotid-cavernous fistula, and need for vascular occlusion ${ }^{45,46}$. Although one could hypothesize that vessels-encroaching tumours should be referred to radiation oncologists, vascular toxicity actually represents a major concern even in patients undergoing RT that can considerably limit dose delivery in areas neighboring the vessel (Fig. 3). In this scenario, the expertise of a neuroradiologist, interventional radiologist, and neurosurgeon might be game changing in selected cases.

The first step is to adequately analyze the critical relationship to the vessel through CT/MRI angiography ${ }^{19}$. The second is to test the tolerance of a potential ICA occlusion through a temporary occlusion test, which can be achieved via external compression or transarterial balloon occlusion. Tolerance can be evaluated through a combination of several techniques including clinical assessment, cross flow tim- 


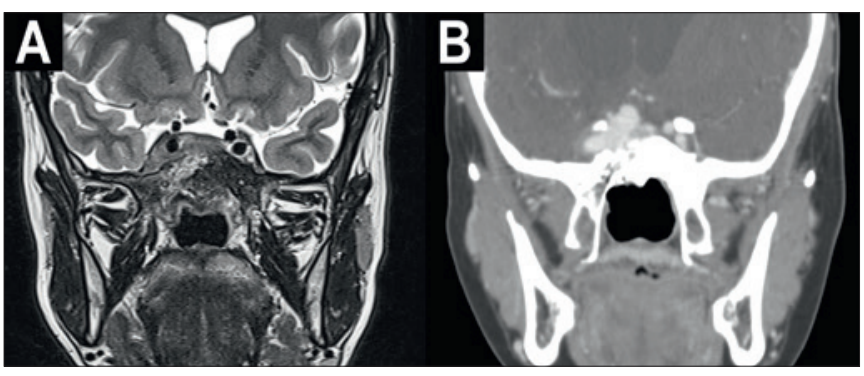

Figure 3. (A, B) The panel shows the case of a pseudoaneurysm of the parasellar, paraclinoid, and intracranial tracts of the right internal carotid artery in a patient who was treated through ${ }^{12} \mathrm{C}$-carbon ion therapy for an unresectable adenoid cystic carcinoma of the right sphenoid sinus.

ing, evoked potentials, and functional imaging. In patients demonstrating adequate cross flow from the contralateral vascular system, the decision on whether or not to perform endovascular ICA occlusion prior to surgery should be based on the estimated risk of intraoperative rupture, which has a known lethality of roughly $7-15 \%{ }^{46,47}$, and possible need for vessel removal as part of the resection ${ }^{48}$. However, preoperative endovascular ICA occlusion should not be indicated carelessly, as the long-term effects of the procedure are unknown. In patients who would not tolerate ICA occlusion, adequate counselling on potential morbidity and mortality is mandatory and strategies such as endovascular flow diverter protective stenting or extracranial-to-intracranial bypass surgery should be considered when surgery can be staged or delayed while the patient undergoes double antiplatelet therapy (Fig. 4) ${ }^{49,50}$.

\section{Intracranial tumour extensions exceeding the rhinologist's expertise}

The definition of intracranial involvement is of utmost importance in planning treatment for sinonasal tumours. MRI with contrast enhancement plays a key role in the delineation of the tumour-dura and tumour-brain interface. Specifically, the disappearance of the three "sandwich" layers with different signals at the anterior cranial fossa (ACF) floor (bone-periosteum, dura, and CSF) and/or the evidence of brain edema surrounding the tumour on T2-weighted images are predictors of intracranial and brain invasion, respectively ${ }^{25}$.

Historically, the gold standard in the treatment of sinonasal malignancies invading the ACF was anterior craniofacial resection with or without adjuvant $\mathrm{RT}^{51}$, with bilateral intraorbital and/or optic nerve extension, massive brain infiltration, optic chiasm involvement, distant metastasis, and internal carotid artery encasement being considered as absolute contraindications. By evolving the concepts
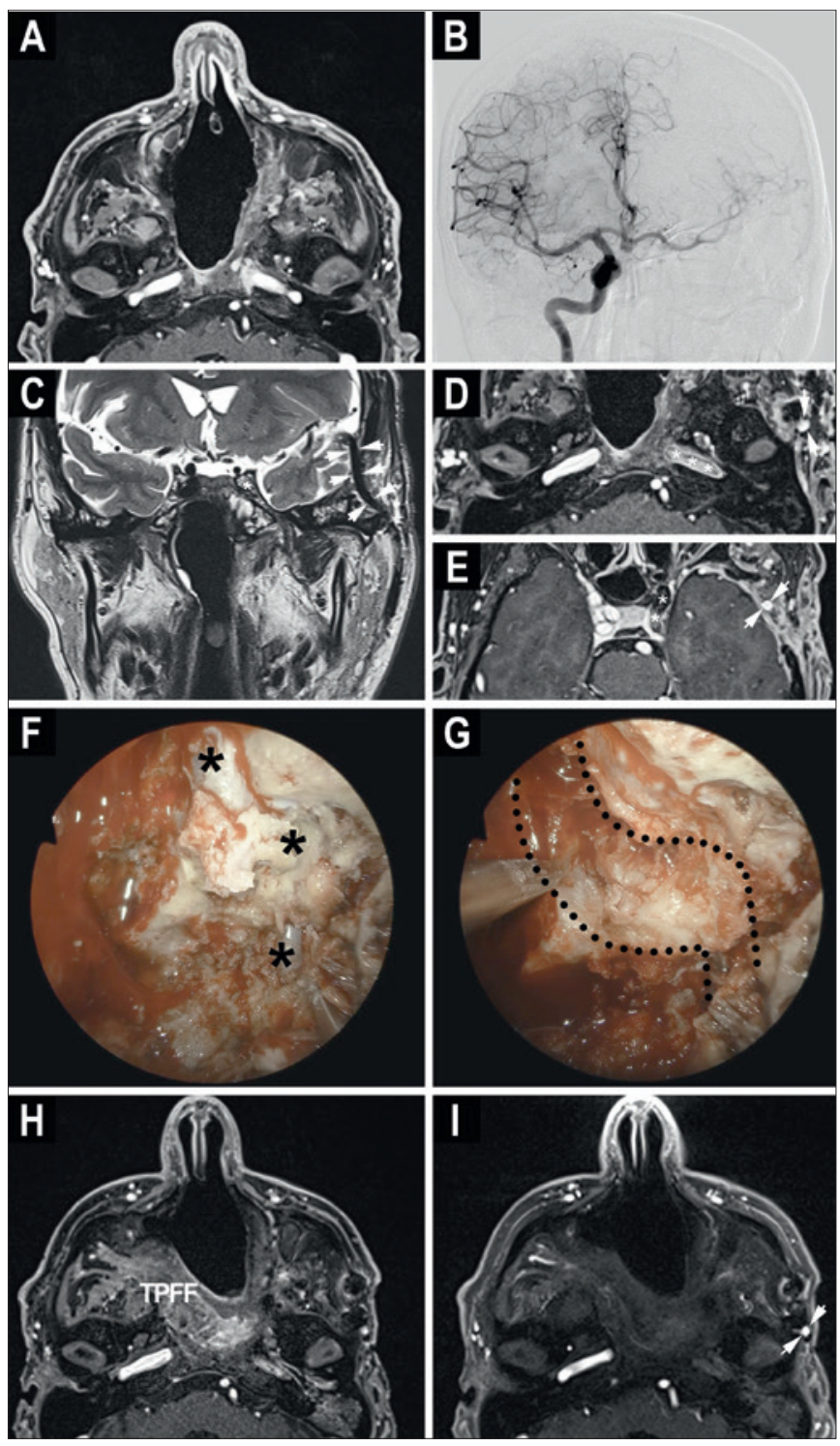

Figure 4. The panel summarizes the complex management of a case of recurrent nasopharyngeal carcinoma. (A) An enhancing nodule corresponding to the second local recurrence of nasopharyngeal carcinoma is identified in close relationship with the anterior genu of the left petrous internal carotid artery. (B) A temporary balloon occlusion test reveals that the closure of the left internal carotid artery would not be tolerated by the patient. (C-E) An extracranialto-intracranial vascular bypass (white arrows) from the left external carotid artery to the left middle cerebral artery was harvested and the left internal carotid artery was closed transarterially (white asterisks). (F, G) A type 3 left nasopharyngeal endoscopic resection was completed and the ipsilateral internal carotid artery (black asterisks) was resected; the carotid canal (black dotted lines) was completely drilled out. (H, I) Follow-up imaging showing patency of the vascular bypass and viability of the right temporoparietal fascia flap (TPFF) employed to resurface the surgical cavity.

of subfrontal-subcranial approach firstly developed by Raveh ${ }^{52,53}$, in the late '90s endoscopic techniques were introduced in adjunction to open approaches with favorable outcomes ${ }^{54}$. The so-called cranioendoscopic approach 
(CEA) combines an endoscopic approach allowing tumour removal from the nasal side with a subfrontal craniotomy that gives wide exposure of the lesion and margin control from above. Main indications for CEA are massive infiltration of the dura, in particular when the dura is involved in proximity to the lamina papyracea or when dural resection would extend far lateral over the orbital roof ${ }^{55}$. Multidisciplinary parallel dissection performed by skilled neurosurgical and otorhinolaryngological teams in CEA, using the microscope and endoscopes respectively, offers accurate control of the resection with clear dural margins. Another scenario that should prompt to consider CEA is the contact between tumour and brain, "even with possible limited infiltration" ${ }^{54}$. Nowadays this can be probably considered a "relative" indication to CEA, or at least a condition mandating an accurate case-by-case selection. During the last two decades, in fact, the growing body of evidence in the field of endoscopic approaches to the nose and paranasal sinuses has paved the way for the first series of pure endoscopic transnasal brain resection in the context of sinonasal malignancies ${ }^{56}$. In cases of limited brain invasion, the proposed technique takes advantage of subpial dissection of the gyrus rectus and/or medial orbital gyrus, with the aim of achieving negative margins of resection. This resection technique requires proper preparation and experience in open and endoscopic approaches to the ACF, including adequate training in dissecting the bony and the dura layers in the context of transnasal craniectomies ${ }^{57,58}$. A series of 19 selected patients with clinically suspected brain infiltration (11 with pathologically-proven brain involvement) including different histologies ( $>50 \%$ ONB) was recently published by the Brescia and Varese groups ${ }^{56}$, showing that 3-year overall, local recurrence-free, and distance recurrence-free survivals were $65.5 \%, 81.8 \%$, and $68.2 \%$, respectively.

Even in referral centers for endoscopic approaches to the ACF, open approaches to the anterior skull base find their place in case of wide dural involvement, especially with lateral extension or when the tumour abuts the optic chiasm or extends over the orbital roof reaching beyond the midpupillary line.

Massive extension of the tumour through the dura and infiltration of falx/superior sagittal sinus and/or brain parenchyma also requires an open approach. In addition, a critical relationship with neurovascular structures as well as infiltration of the anterior wall of the frontal sinus or massive frontal sinus involvement are contraindications for purely endoscopic approaches to the $\mathrm{ACF}^{59}$. Furthermore, staged surgery should be considered when the tumour cannot be entirely accessed through a single approach that might require extensive bone removal or be threatened by significant blood loss, as may occur even for benign lesions like JA ${ }^{60}$. Procedure staging would enable complete resection, minimizing the risks related to duration of surgery and surgeons' fatigue ${ }^{61}$.

Finally, surgeons must bear in mind that resectability of sinonasal tumours with intracranial extension is influenced not only by the entity of brain and dural invasion itself, but also by the histological diagnosis, with poorly differentiated/aggressive lesions benefitting mostly from multimodal treatment often including neoadjuvant therapy.

\section{Orbital tumour extensions exceeding the rhinologist's expertise}

The degree of orbital encroachment is a key element for planning treatment of sinonasal tumours. In the ' 70 s, erosion of the lamina papyracea by sinonasal cancers was considered as an indication to orbital exenteration ${ }^{51}$. Over the last decades, several groups have demonstrated the oncologic safety of orbit-sparing surgery in adequately selected cases ${ }^{62-65}$; however, criteria guiding orbit-sparing surgery still lack univocal consensus ${ }^{66-69}$. Since the first proposal in the '80s of sparing the orbit in tumours eroding the medial orbital bony wall by Perry et al. ${ }^{63}$ and Scott McCary et al. ${ }^{64}$, the decisional barriers to indicate the need for orbital exenteration has been settled to the involvement of extrinsic muscles, optic nerve, ocular bulb, and/or skin overlying the eyelid, as described by Iannetti et al. in the early $2000 \mathrm{~s}^{70}$. More recently, endoscopic and endoscopic-assisted orbitsparing surgery was shown to be useful and oncologically safe ${ }^{71}$. Turri-Zanoni et al. described a multimodal treatment algorithm for sinonasal cancers with orbital invasion based on histology-driven treatment and accurate staging of the degree of orbital invasion through contemporary preoperative imaging (Figs. 5, 6) ${ }^{72}$. Poorly differentiated cancers without orbital apex involvement were submitted to neoadjuvant chemotherapy, which was continued up to a maximum of 5 cycles in good responders. Patients achieving complete response or $\geq 80 \%$ reduction of initial tumour volume at the end of neoadjuvant chemotherapy were sent for definitive chemoradiation; patients with less favorable response to neoadjuvant chemotherapy underwent surgical resection followed by adjuvant radiotherapy or chemoradiotherapy. Patients whose general conditions prevented chemotherapy and those affected by well differentiated sinonasal cancers or chemoresistant tumours received primary surgery, which was followed by adjuvant treatment if mandated by risk factors identified at definitive histologic examination. The multimodal treatment algorithm maximized the orbital preservation rate $(76.6 \%)$ in patients with orbit-encroaching sinonasal cancer. According to a recent 

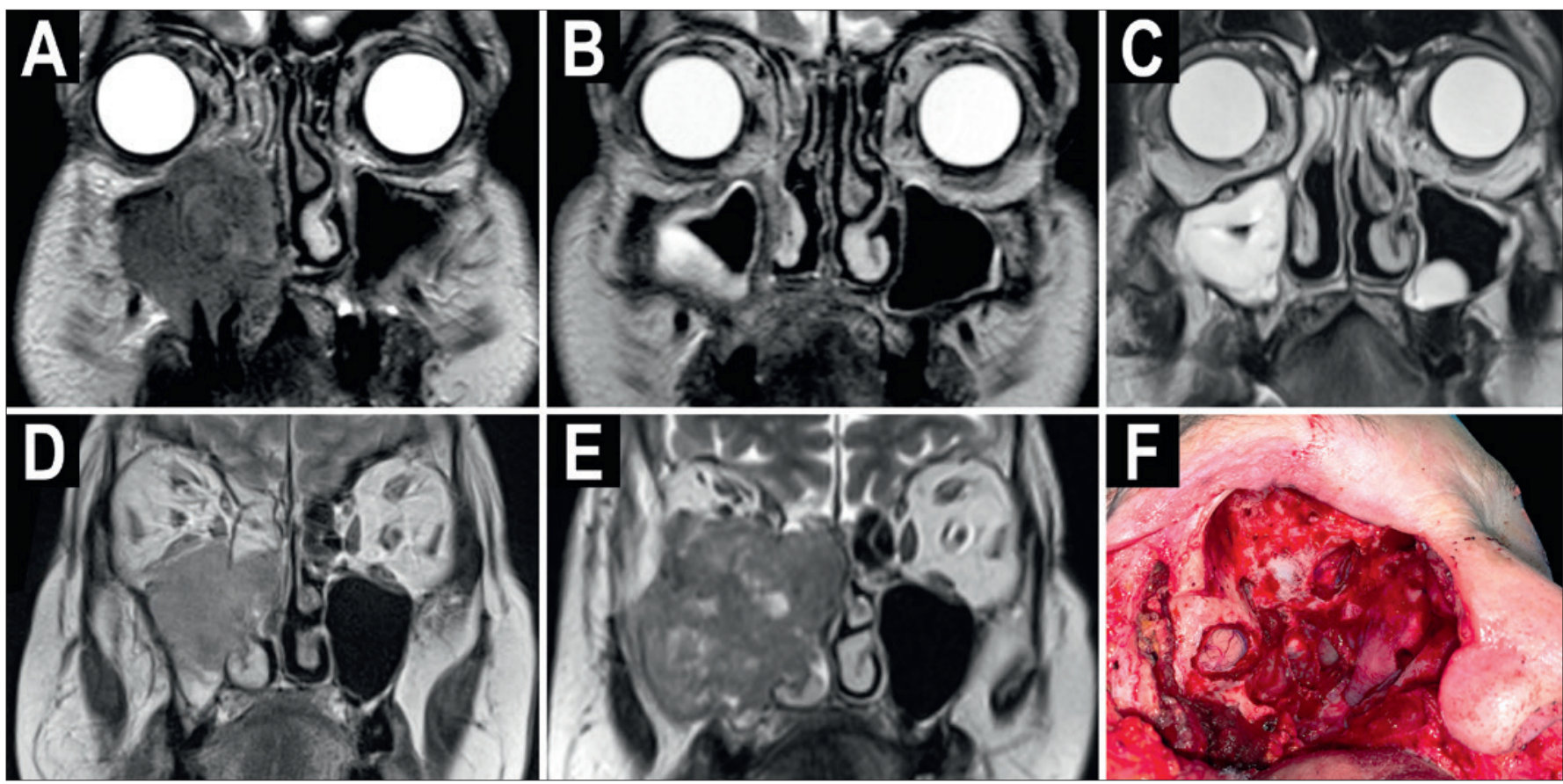

Figure 5. The panel illustrates two cases of moderately differentiated squamous cell carcinoma of the right maxillary sinus (A, D), both receiving neoadjuvant chemotherapy with taxane, cisplatin, and 5-fluorouracile as the primary treatment modality. The first tumour (A) had a partial response (B) and was therefore sent for proton therapy, which resulted in a complete response (C). The second tumour (D) had progression of disease (E) and therefore mandated surgery including total maxillectomy with orbital exenteration, middle and anterior craniectomy with dural resection $(\mathbf{F})$, reconstruction of the defect through a multilayer skull base plasty and an anterolateral thigh free flap, followed by adjuvant radiation therapy.

publication, patients receiving orbital ablation for a sinonasal cancer unamenable to orbit-sparing surgery have a high probability of bearing nodal disease $(29.8 \%)$, poor chances of surviving (5-year overall and disease-specific survival: $27.8 \%$ ), and high risk of experiencing a local relapse despite aggressive surgery (5-year local recurrence-free survival: $44.6 \%)^{28}$. These data should be considered as a "red flag" for the MDT, with an indication to orbital ablation deserving thoughtful evaluation of potential alternatives.

The need to combine orbit sparing with functional preservation and offer the patient an adequately experienced handling of orbital tissues justifies why an oculoplastic surgeon should be part of the MDT. For instance, Shi et al. described the feasibility and oncologic adequacy of a combined external and endoscopic en bloc orbit-sparing resection in malignancies arising from the lacrimal drainage system ${ }^{73}$. Recently, Fontes et al. reported on the satisfactory functional outcome of surgical reconstruction of the medial rectus muscle after iatrogenic rupture during endoscopic transnasal sinus surgery ${ }^{74}$. Based on these results and keeping in mind the potential negative effects of adjuvant treatment, one could hypothesize to partially resect and primarily reconstruct a focally-invaded extrinsic ocular muscle. This approach could indeed reduce morbidity of treatment in patients who will have an ominous prognosis irrespective of surgical aggressiveness. However, this additional step forward in surgical orbital preservation would be unfeasible without the contribution of oculoplastic surgeons and/or maxillofacial surgeons trained in oculoplastic surgery.

Another unsolved challenge of sinonasal oncology is represented by sinonasal cancers macroscopically invading the orbital apex. When invasion of the orbital apex is detected at preoperative imaging, 5-year overall survival probability is as low as $15.0 \%$ in patients undergoing multimodal treatment including orbital exenteration/clearance ${ }^{28}$. Sugawara et al. reported a 5-year overall survival rate of $86.2 \%$ in 15 patients with macroscopic orbital apex involvement treated through an "extended orbital exenteration" 75 . The surgical procedure was performed by a multispecialty team composed of neurosurgeons, head and neck surgeons, and plastic surgeons. In addition to resection of the nasoethmoidal box and anterior skull base, the authors removed the orbital apex as surrounded by its bony walls and sectioned the neurovascular structures in their intracranial tracts through a transcranial approach. The obvious gain in overall survival reported by Sugawara et al. should encourage one to offer multidisciplinary surgery by both head and neck and neu- 

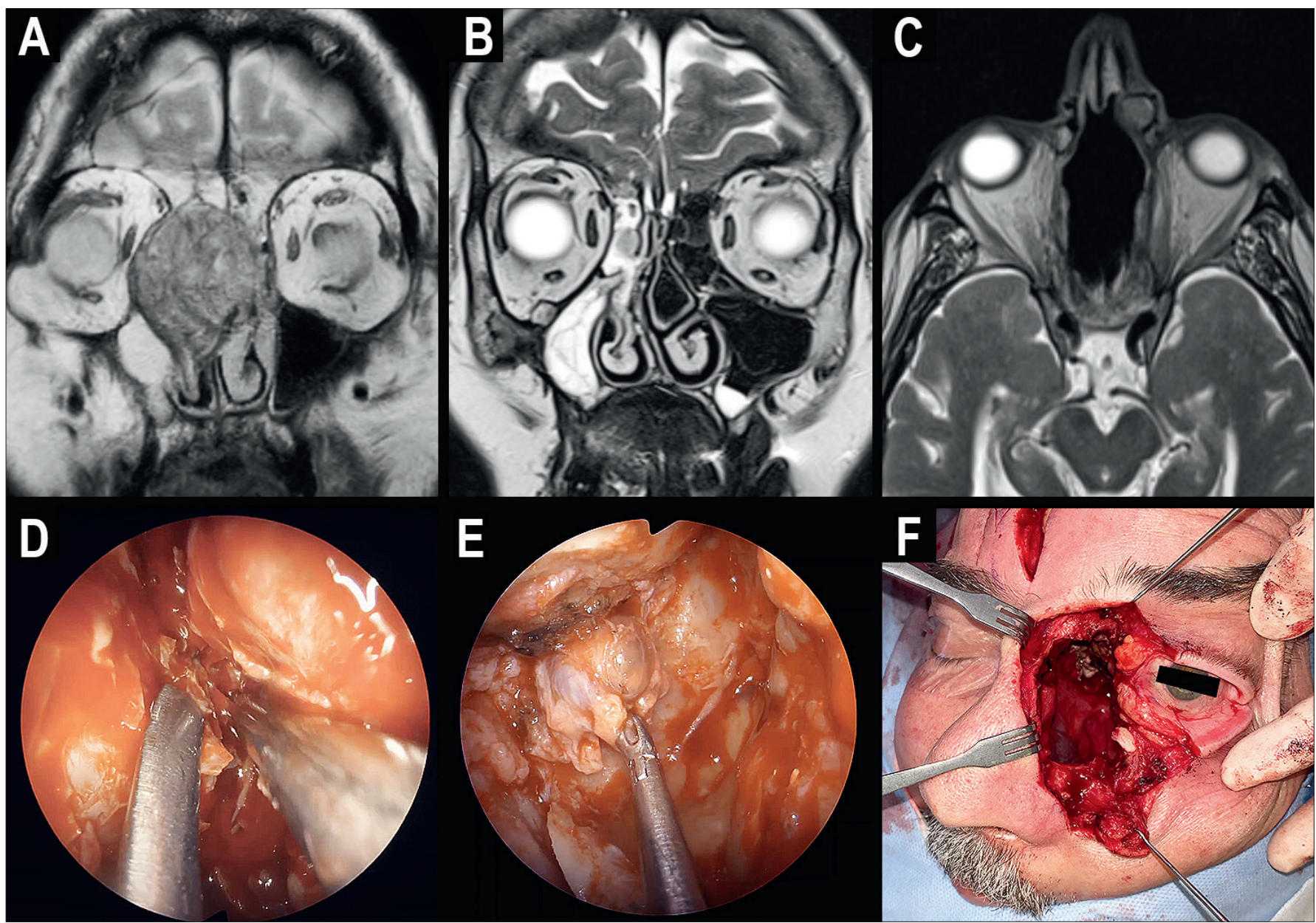

Figure 6. Panel showing three examples of surgical orbital preservation in patients affected by sinonasal cancers. (A, D) A right nasoethmoidal intestinal-type adenocarcinoma encroaching the orbit with no interruption of the periorbit at preoperative imaging was resected through an orbit-sparing endoscopic approach. (B, E) A recurrent adenoid cystic carcinoma located into the inferior aspect of the right orbital cavity was resected through an orbit-sparing transnasal endoscopic prelacrimal approach. (C, F) A unifocal, left preseptal recurrence of intestinal-type adenocarcinoma was resected through an orbit-sparing rhinectomy extended to the medial canthus and lacrimal sac.

rological surgeons to those unfortunate patients requiring orbital ablation for an orbital apex-invading cancer.

\section{Post-ablative defects requiring plastic surgical expertise}

The majority of resections for sinonasal tumours with cranial involvement result in skull base defects that can be effectively reconstructed by an otorhinolaryngologist and/or neurosurgeon through multilayer reconstruction possibly including a vascularized flap ${ }^{76-79}$. Regional flaps such as the pericranial or temporoparietal fascia flap can be used upfront or left as backup options when the risk of postoperative CSF leak is deemed high (Fig. 7) ${ }^{80,81}$.

In rarer circumstances, the defect can be variably extended to the external nose, orbit, midface, upper face, maxillo- facial skeleton, oral cavity, and/or scalp, which mandates the use of more complex reconstructive strategies. Another scenario that requires advanced plastic surgery expertise is when graft-based and vascularized local and regional reconstructive strategies are unavailable or have already failed ${ }^{82-86}$. In both circumstances, reconstruction with revascularized free flaps has been reported as an effective strategy ${ }^{87}$. A variety of free flaps have been used in patients requiring complex skull base reconstruction. According to a recent systematic review, 1628 cases of skull base reconstruction using free flap as the sole strategy or in combination with other techniques have been reported, with the large majority of cases including an anterior skull base defect ${ }^{88}$. Fasciocutaneous flap such as the anterolateral thigh and radial forearm free flaps have been most frequently employed, with bulkier myocutaneous flaps such as the 


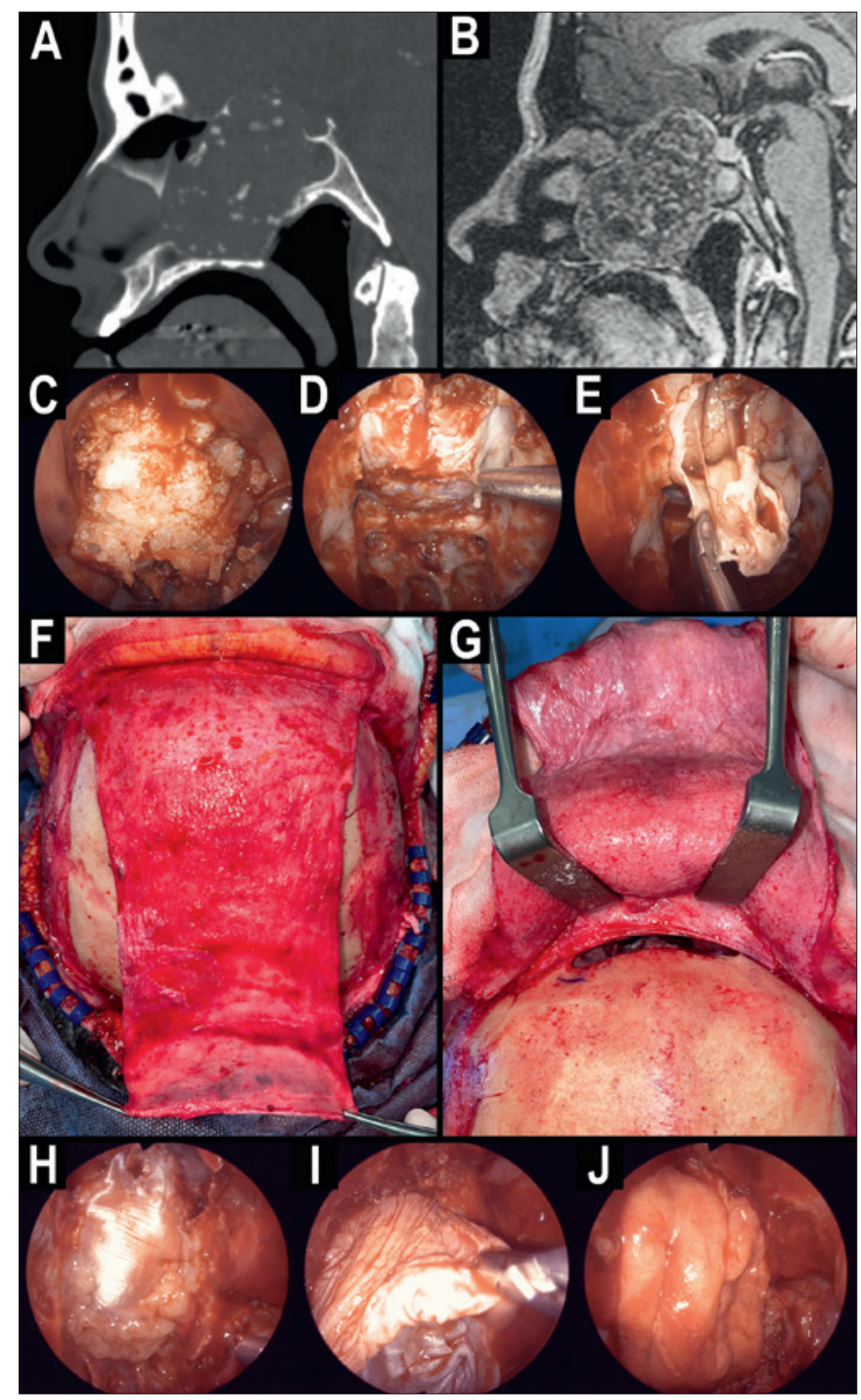

Figure 7. Panel illustrating the surgical management of a chondrosarcoma of the nasal septum encroaching the anterior skull base. (A, B) Preoperative imaging of the tumour. (C-E) Exemplificative steps of the endoscopic transnasal resection of the chondrosarcoma. $(\mathbf{F}, \mathbf{G})$ Harvest of the pericranial flap and preparation of the so-called "mailbox" for flap transposition towards the skull base defect. (H-J) Three-layer reconstruction of the skull base through grafts of iliotibial tract and subcutaneous fat, which was lined with a pericranial flap.

rectus abdominis and latissimus dorsi flap being indicated for very large defects. Bone-including free flaps have also been reported for reconstruction requiring a rigid vascularized framework, with special reference to those harvested from the subscapular system due to its versatility in terms of bony and soft tissue components ${ }^{89,90}$. Skull base infection and osteoradionecrosis also benefit from transfer of non-infected, non-irradiated, (re-)vascularized tissue following necrosectomy and debridement, which should be delivered in the context of a comprehensive therapy includ- ing a combination of tailored antibiotics, pentoxifylline, alpha-tocopherol, and hyperbaric oxygen therapy ${ }^{91-93}$.

Of note, it is the authors' opinion that reconstruction of the bony and dural defect in the skull base should adhere to the principles of a multilayer technique to ensure watertight closure before the free flap is in-set. It is indeed surmised that this minimizes the chances of CSF leak, which can subtly occur even though a thick layer of well vascularized tissues covers the defect, but skull base closure is not watertight. Considering this, it seems logical that a plastic surgeon or head and neck surgeon with expertise in plastic surgery be included in MDT for advanced sinonasal tumours. Moreover, adequate briefing and planning of the reconstruction is mandatory, with each surgical specialist being in charge of different phases of reconstruction including multilayer skull base reconstruction, flap harvesting, in-set, and microvascular anastomoses (Fig. 8).

\section{Intraoperative complications requiring multidisciplinary management}

Several intraoperative complications can occur during surgery for advanced sinonasal tumours. The present paragraph summarizes the main concepts on two important events of which the MDT should be aware, namely intraoperative ICA rupture and neurogenic cardiovascular alterations.

Injury of the ICA is a rare but potentially catastrophic intraoperative complication of endoscopic skull base surgery. Wang et al. reported that an incidence of $0.016 \%$ to $1 \%$ was estimated based on large endoscopic transnasal surgery series ${ }^{94}$; AlQahtani et al. reported an in-depth analysis of 28 cases of ICA injury out of 7160 endoscopic procedures, with a resulting frequency of $0.4 \%{ }^{46}$.

In case of intraoperative ICA rupture, the current opinion is that bleeding should be temporarily controlled by nasal packing possibly anticipated by an attempt at direct endoscopic hemostasis by an adequately trained surgical team ${ }^{47,95}$. This explains why the anesthesiologist should also be considered as part of the MDT. For instance, optimal blood pressure control is warranted in case of ICA injury ${ }^{96}$, with arterial hypotension and hypertension being sequentially necessary to facilitate bleeding control and ensure adequate collateral/contralateral flow towards ischemic areas, respectively. Adequate preoperative briefing with the anesthesiologist is therefore suggested in cases with potential ICA injury. Thereafter, the patient should be moved to the angiography room and urgent occlusion test followed by endovascular stenting and/or occlusion should be performed by an interventional radiologist $95,97,98$. 


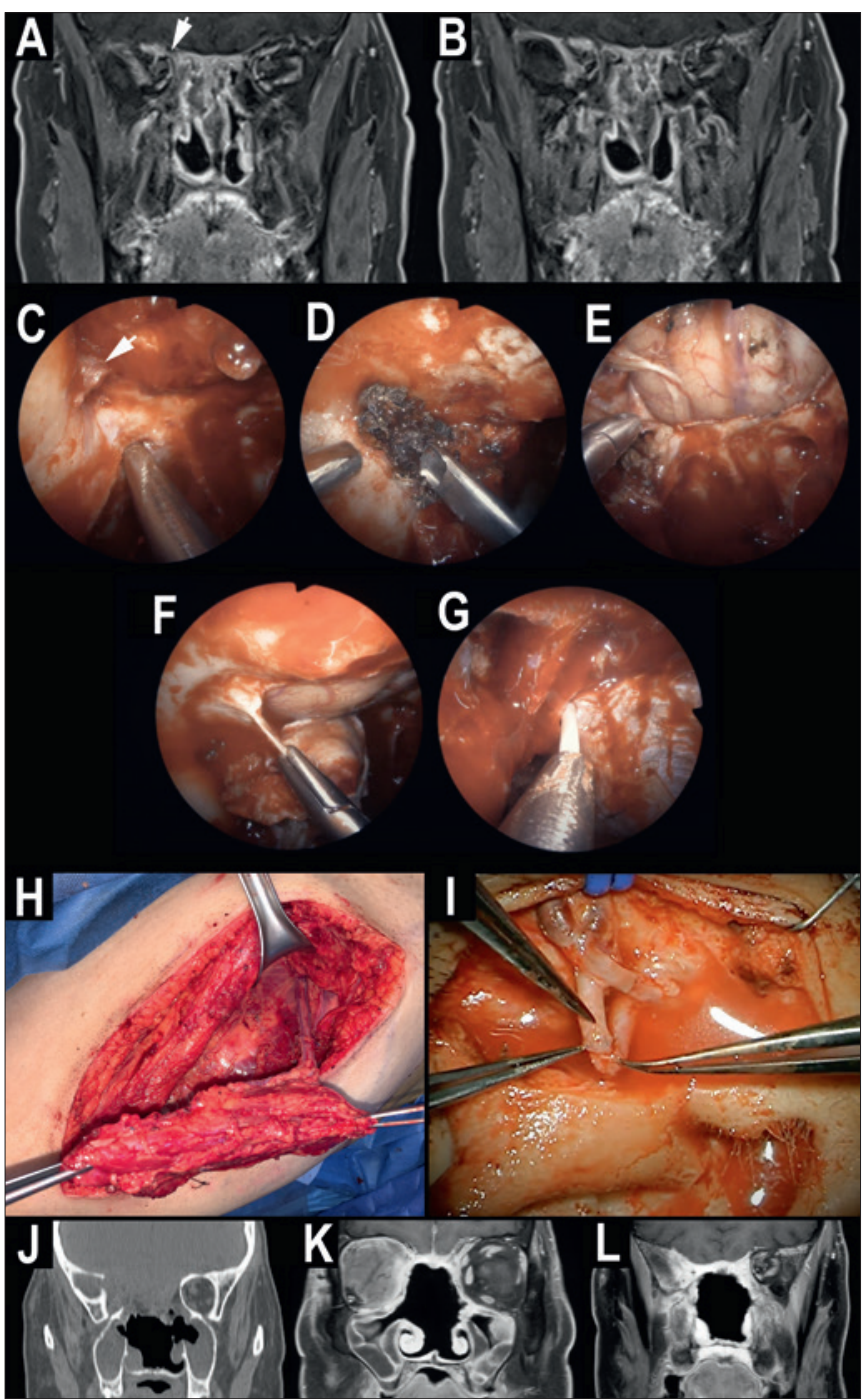

Figure 8. Panel illustrating the complex surgical management of a recurrent nasopharyngeal carcinoma located into the nasoethmoidal box (A, B) and extending to the right orbital apex through the posterior ethmoidal canal (white arrow). (C-G). Main phases of the first part of the surgical procedure, which includes endoscopic resection with transnasal craniectomy, orbital exenteration, and three-layer reconstruction of the skull base with iliotibial tract and subcutaneous fat. (H, I) Harvesting and microvascular anastomosis to the right superficial temporal pedicle of a left muscular anterolateral thigh flap used to fill the orbital cavity and line the posterior portion of the skull base reconstruction. (J) Early postoperative computed tomography scan showing the lateral and posterior extent of the bony defect. $(\mathbf{K}, \mathbf{L})$ Postoperative MRI acquired before re-irradiation with proton therapy; contrast-enhanced images demonstrate pedicle patency and adequate vascularization of the skull base plasty.

As a consequence, the interventional radiology unit should be notified when surgery with non-negligible risk of ICA injury is performed. Rupture of vessels other than the ICA might also need radiologic interventional procedures or even transcranial open surgery when primary hemostasis cannot be achieved. Therefore, if not directly involved in the surgical procedure, a neurosurgeon, preferably trained in bypass surgery, should be alerted when an operation at risk of causing an intraoperative intracranial bleeding is performed.

In case of endoscopic surgery involving any part of the trigeminal nerve, adequate briefing with the anesthesiologist is also mandatory. In fact, trigeminal stimulation might suddenly provoke dysrhythmia, hypotension, or even asystole due to the trigemino-cardiac reflex ${ }^{99,100}$. Management of the trigemino-cardiac reflex is mainly based on preoperative risk evaluation, vigilance during anesthesia, effective communication for a rapid cessation of precipitating stimuli, and prompt correction of cardiovascular changes.

\section{Conclusions}

The present narrative review highlighted that most cases of advanced sinonasal tumours can be managed by an adequately trained otorhinolaryngological team. However, since a minor yet non-negligible case rate requires additional expertise, a systematic MDT discussion of sinonasal tumours have, among others, the advantage of selecting patients requiring the intraoperative skills of neurosurgeons, oculoplastic surgeons, and physicians with plastic surgery training. As a final remark, one should consider that nonsurgical specialties participating in the MDT approach to sinonasal tumours have been and are noticeably evolving. As a consequence, the paradigms of treatment of sinonasal tumours, with special reference to cancers and selected advanced benign tumours, are considerably changing. This fact mandates approaching advanced sinonasal tumours through a comprehensive MDT approach to provide the patient with the best possible treatment he/she can be offered.

\section{References}

Licitra L, Keilholz U, Tahara M, et al. Evaluation of the benefit and use of multidisciplinary teams in the treatment of head and neck cancer. Oral Oncol 2016;59:73-79. https://doi.org/10.1016/j. oraloncology.2016.06.002

2 Teitelbaum JI, Issa K, Barak IR, et al. Sinonasal squamous cell carcinoma outcomes: does treatment at a high-volume center confer survival benefit? Otolaryngol - Head Neck Surg 2020;163:986-991. https://doi.org/10.1177/0194599820935395

Lehrich BM, Yasaka TM, Goshtasbi K, et al. Outcomes of primary versus salvage surgery for sinonasal malignancies: a populationbased analysis. Laryngoscope 2021;131:E710-E718. https://doi. org/10.1002/lary.28925.

4 Bridge JA, Bowen JM, Smith RB. The small round blue cell tumours of the sinonasal area. Head Neck Pathol 2010;4:84-93. https://doi. org/10.1007/s12105-009-0158-6

Rooper LM, Bishop JA. Sinonasal small round blue cell tumours: an immunohistochemical approach. Surg Pathol Clin 2017;10:103-123. https://doi.org/10.1016/j.path.2016.10.005

6 Ozturk K, Gencturk M, Caicedo-Granados E, et al. Positron emission 
computed tomography and magnetic resonance imaging features of sinonasal small round blue cell tumours. Neuroradiol J 2020;33:4856. https://doi.org/10.1177/1971400919873895

7 Schreiber A, Rampinelli V, Ferrari M, et al. Diagnostic reliability of pretreatment biopsy in malignant nasoethmoidal tumours: a retrospective study of 77 cases. Laryngoscope 2018;128:1772-1777. https://doi.org/10.1002/lary.27077

8 Thompson LDR, Franchi A. New tumour entities in the $4^{\text {th }}$ edition of the World Health Organization classification of head and neck tumours: nasal cavity, paranasal sinuses and skull base. Virchows Arch 2018;472:315-330. https://doi.org/10.1007/s00428-017-2116-0

9 Frierson HF, Mills SE, Fechner RE, et al. Sinonasal undifferentiated carcinoma. An aggressive neoplasm derived from Schneiderian epithelium and distinct from olfactory neuroblastoma. Am J Surg Pathol 1986;10:771-779. https://doi. org/10.1097/00000478-198611000-00004

10 Agaimy A, Franchi A, Lund VJ, et al. Sinonasal Undifferentiated Carcinoma (SNUC): from an entity to morphologic pattern and back again-a historical perspective. Adv Anat Pathol 2020;27:51-60. https://doi.org/10.1097/PAP.0000000000000258

11 Kakkar A, Antony VM, Pramanik R, et al. SMARCB1 (INI1) - deficient sinonasal carcinoma: a series of 13 cases with assessment of histologic patterns. Hum Pathol 2019;83:59-67. https://doi. org/10.1016/j.humpath.2018.08.008

12 Agaimy A, Weichert W. SMARCA4-deficient sinonasal carcinoma. Head Neck Pathol 2017;11:541-545. https://doi.org/10.1007/ s12105-017-0783-4

13 Riobello C, López-Hernández A, Cabal VN, et al. IDH2 mutation analysis in undifferentiated and poorly differentiated sinonasal carcinomas for diagnosis and clinical management. Am J Surg Pathol 2020;44:396-405. https://doi.org/10.1097/PAS.0000000000001420

14 Baraban E, Tong CCL, Adappa ND, et al. A subset of sinonasal undifferentiated carcinoma is associated with transcriptionally active high-risk human papillomavirus by in situ hybridization: a clinical and pathologic analysis. Hum Pathol 2020;101:64-69. https://doi. org/10.1016/j.humpath.2020.05.002

15 Stelow EB, Bellizzi AM, Taneja K, et al. NUT rearrangement in undifferentiated carcinomas of the upper aerodigestive tract. Am J Surg Pathol 2008;32:828-834. https://doi.org/10.1097/ PAS.0b013e31815a3900

16 El-Naggar AK, Chan JKC, Rubin Grandis J, et al. WHO classification of head and neck tumours. WHO classification of tumours. Fourth Edition, Vol 9. Lyon: International Agency for Research on Cancer (IARC); 2017.

17 Mehrad M, Chernock RD, El-Mofty SK, et al. Diagnostic discrepancies in mandatory slide review of extradepartmental head and neck cases: experience at a large academic center. Arch Pathol Lab Med 2015;139:1539-1545. https://doi.org/10.5858/arpa.2014-0628-OA.

18 Ganti A, Tajudeen BA, Plitt MA, et al. Discordance in preoperative and postoperative histopathology of sinonasal tumours. Am J Rhinol Allergy 2018;32:101-105. https://doi.org/10.1177/1945892418762845

19 Maroldi R, Borghesi A, Ravanelli M, et al. The role of morphologic and functional imaging in pretreatment assessment. Adv Otorhinolaryngol 2020;84:28-45. https://doi.org/10.1159/000457923

20 Som PM, Shugar JMA. The significance of bone expansion associated with the diagnosis of malignant tumours of the paranasal sinuses. Radiology 1980;136:97-100. https://doi.org/10.1148/ radiology.136.1.7384530

21 Som PM, Lawson W, Lidov MW. Simulated aggressive skull base erosion in response to benign sinonasal disease. Radiology 1991;180:755-759. https://doi.org/10.1148/radiology.180.3.1871290

22 Kimmelman CP, Korovin GS. Management of paranasal sinus neo- plasms invading the orbit. Otolaryngol Clin North Am 1988;21:77-92. https://doi.org/10.1016/s0030-6665(20)31567-X

23 Som PM, Braun IF, Shapiro MD, et al. Tumours of the parapharyngeal space and upper neck: MR imaging characteristics. Radiology 1987;164:823-829. https://doi.org/10.1148/radiology.164.3.3039571

24 Eisen MD, Yousem DM, Montone KT, et al. Use of preoperative MR to predict dural, perineural, and venous sinus invasion of skull base tumours. Am J Neuroradiol 1996;17:1937-1945.

25 Maroldi R, Nicolai P. Imaging in treatment planning for sinonasal diseases. Berlin, Heidelberg: Springer; 2006. https://doi. org/10.1177/000348940611500218

26 Giacchi RJ, Lebowitz RA, Yee HT, et al. Histopathologic evaluation of the ethmoid bone in chronic sinusitis. Am J Rhinol 2001;15:193197. https://doi.org/10.2500/105065801779954148

27 Maroldi R, Farina D, Battaglia G, et al. MR of malignant nasosinusal neoplasms frequently asked questions. Eur J Radiol 1997;24:181-190. https://doi.org/10.1016/S0720-048X(97)01183-2

28 Ferrari M, Migliorati S, Tomasoni M, et al. Sinonasal cancer encroaching the orbit: ablation or preservation? Oral Oncol 2021;114:105185. https://doi.org/10.1016/j.oraloncology.2021.105185.

29 Kraus DH, Sterman BM, Levine HL, et al. Factors influencing survival in ethmoid sinus cancer. Arch Otolaryngol Neck Surg 1992;118:367372. https://doi.org/10.1001/archotol.1992.01880040025005

30 Shah JP, Kraus DH, Bilsky MH, et al. Craniofacial resection for malignant tumours involving the anterior skull base. Arch Otolaryngol - Head Neck Surg 1997;123:1312-1317. https://doi.org/10.1001/ archotol.1997.01900120062010

31 Schmalbach CE, Gourin C. Managing vascular tumours - open approaches. Otolaryngol Clin North Am 2016;49:777-790. https://doi. org/10.1016/j.otc.2016.03.001

32 Snyderman $\mathrm{CH}$, Pant H. Endoscopic management of vascular sinonasal tumours, including angiofibroma. Otolaryngol Clin North Am 2016;49:791-807. https://doi.org/10.1016/j.otc.2016.02.009

33 Bertazzoni G, Schreiber A, Ferrari M, et al. Contemporary management of juvenile angiofibroma. Curr Opin Otolaryngol Head Neck Surg 2019;27:47-53. https://doi.org/10.1097/MOO.0000000000000505

34 de Almeida Vital JM, de Farias TP, Dias FL, et al. Nasal cavity paraganglioma: literature review and discussion of a rare case. Biomed Hub 2017;2:1-15. https://doi.org/10.1159/000464099

35 Simmonds JC, Rebeiz EE. Surgical resection of sinonasal hemangiopericytoma involving anterior skull base: case reports and literature review. Am J Otolaryngol - Head Neck Med Surg 2017;38:87-91. https://doi.org/10.1016/j.amjoto.2016.09.003

36 Schlosser RJ, Woodworth BA, Gillespie MB, et al. Endoscopic resection of sinonasal hemangiomas and hemangiopericytomas. ORL J Otorhinolaryngol Relat Spec 2006;68:69-72. https://doi.org/ 10.1159/000091092.

37 Anzai T, Ito S, Yamashita A, et al. Surgical management of bilateral venous malformation (cavernous hemangiomas) of the maxillary sinus. Case Rep Otolaryngol 2020;2020:8606103. https://doi. org/10.1155/2020/8606103.

38 Nelson BL, Thompson LDR. Sinonasal tract angiosarcoma: a clinicopathologic and immunophenotypic study of 10 cases with a review of the literature. Head Neck Pathol 2007;1:1-12. https://doi.org/10.1007/ s12105-007-0017-2

39 Belotti F, Ferrari M, Doglietto F, et al. Ophthalmic artery originating from the anterior cerebral artery: anatomo-radiological study, histological analysis, and literature review. Neurosurg Rev 2016;39:483493. https://doi.org/10.1007/s10143-016-0715-x

40 Duffis EJ, Gandhi CD, Prestigiacomo CJ, et al. Head, neck, and brain 
tumour embolization guidelines. J Neurointerv Surg 2012;4:251-255. https://doi.org/10.1136/neurintsurg-2012-010350

${ }_{41}$ Ciceri EF, Plebani M, Augelli R, et al. Transnasal devascularisation of a sinonasal hypervascular tumour (glomangiopericytoma) with direct injection of liquid polymer agent $\left(\right.$ Squid $\left.^{\circledR}\right)$. Interv Neuroradiol 2019;25:230-233. https://doi.org/10.1177/1591019918805776

42 Langdon C, Herman P, Verillaud B, et al. Expanded endoscopic endonasal surgery for advanced stage juvenile angiofibromas: a retrospective multi-center study. Rhinol J 2017;54:239-246. https://doi. org/10.4193/rhin15.104

43 Nicolai P, Schreiber A, Bolzoni Villaret A. juvenile angiofibroma: evolution of management. Int J Pediatr 2012,2012:1-11. https://doi. org/10.1155/2012/412545

44 Maroda AJ, Beckmann NA, Sheyn AM, et al. Trimodal embolization of juvenile nasopharyngeal angiofibroma with intracranial extension. Int J Pediatr Otorhinolaryngol 2020;130:109805. https://doi. org/10.1016/j.ijporl.2019.109805

45 Labib MA, Prevedello DM, Carrau R, et al. A road map to the internal carotid artery in expanded endoscopic endonasal approaches to the ventral cranial base. Neurosurgery 2014;10:448-471. https://doi. org/10.1227/NEU.0000000000000362

46 AlQahtani A, London NR, Castelnuovo P, et al. Assessment of factors associated with internal carotid injury in expanded endoscopic endonasal skull base surgery. JAMA Otolaryngol - Head Neck Surg 2020;146:364-372. https://doi.org/10.1001/jamaoto.2019.4864

47 Padhye V, Valentine R, Sacks R, et al. Coping with catastrophe: the value of endoscopic vascular injury training. Int Forum Allergy Rhinol 2015;5:247-252. https://doi.org/10.1002/alr.21471

48 Sekhar LN, Natarajan SK, Ellenbogen RG, et al. Cerebral revascularization for ischemia, aneurysms, and cranial base tumours. Neurosurgery 2008;62:1373-1410. https://doi.org/10.1227/01. neu.0000333803.97703.c6

49 Wolfswinkel EM, Landau MJ, Ravina K, et al. EC-IC bypass for cerebral revascularization following skull base tumour resection: current practices and innovations. J Surg Oncol 2018;118:815-825. https:// doi.org/10.1002/jso.25178

50 Piazza P, Di Lella F, Bacciu A, et al. Preoperative protective stenting of the internal carotid artery in the management of complex head and neck paragangliomas: long-term results. Audiol Neurotol 2013;18:345-352. https://doi.org/10.1159/000354158

51 Ketcham AS, Chretien PB, Van Buren JM, et al. The ethmoid sinuses: a re-evaluation of surgical resection. Am J Surg 1973;126:469-476. https://doi.org/10.1016/S0002-9610(73)80032-7

52 Raveh J, Laedrach K, Speiser M, et al. The subcranial approach for fronto-orbital and anteroposterior skull-base tumours. Arch Otolaryngol Neck Surg 1993;119:385-393. https://doi.org/10.1001/ archotol.1993.01880160029006

53 Raveh J, Turk JB, Ladrach K, et al. Extended anterior subcranial approach for skull base tumours: long-term results. J Neurosurg 1995;82:1002-1010. https://doi.org/10.3171/jns.1995.82.6.1002

54 Nicolai P, Battaglia P, Bignami M, et al. Endoscopic surgery for malignant tumours of the sinonasal tract and adjacent skull base: a 10-year experience. Am J Rhinol 2008;22:308-316. https://doi.org/10.2500/ ajr.2008.22.3170

55 Naunheim MR, Goyal N, Dedmon MM, et al. An algorithm for surgical approach to the anterior skull base. J Neurol Surgery Part B Skull Base 2016;77:364-370. https://doi.org/10.1055/s-0036-1580598

56 Mattavelli D, Ferrari M, Bolzoni Villaret A, et al. Transnasal endoscopic surgery in selected nasal-ethmoidal cancer with suspected brain invasion: indications, technique, and outcomes. Head Neck 2019;41:1854-1862. https://doi.org/10.1002/hed.25621

57 Snyderman C, Kassam A, Carrau R, et al. Acquisition of surgical skills for endonasal skull base surgery: a training program. Laryngoscope 2007;117:699-705. https://doi.org/10.1097/mlg.0b013e318031c817

58 Ferrari M, Bossi P, Mattavelli D, et al. Management of sinonasal adenocarcinomas with anterior skull base extension. J Neurooncol 2020;150:405-417. https://doi.org/10.1007/s11060-019-03385-8

59 Abu-Ghanem S, Shilo S, Yehuda M, et al. Anterior skull base surgery in the $21^{\text {st }}$ century: the role of open approaches. Adv Otorhinolaryngol 2020;84:56-67. https://doi.org/10.1159/000457925

60 Nicolai P, Villaret AB, Farina D, et al. Endoscopic surgery for juvenile angiofibroma: a critical review of indications after 46 cases. Am J Rhinol Allergy 2010;24:e67-72. https://doi.org/10.2500/ ajra.2010.24.3443

61 Snyderman CH, Pant H, Carrau RL, et al. What are the limits of endoscopic sinus surgery? The expanded endonasal approach to the skull base. Keio J Med 2009;58:152-160. https://doi.org/10.2302/ kjm.58.152

62 Imola MJ, Schramm VJ. Orbital preservation in surgical management of sinonasal malignancy. Laryngoscope 2002;112:1357-1365. https:// doi.org/10.1097/00005537-200208000-00007

63 Perry C, Levine PA, Williamson BR, et al. Preservation of the eye in paranasal sinus cancer surgery. Arch Otolaryngol Neck Surg 1988;114:632-634. https://doi.org/10.1001/ archotol.1988.01860180046027

64 Scott McCary W, Levine PA, Cantrell RW. Preservation of the eye in the treatment of sinonasal malignant neoplasms with orbital involvement: a confirmation of the original treatise. Arch Otolaryngol - Head Neck Surg 1996;122:657-659. https://doi.org/10.1001/ archotol.1996.01890180063015

65 Lund VJ, Howard DJ, Wei WI, et al. Craniofacial resection for tumours of the nasal cavity and paranasal sinuses - A 17-year experience. Head Neck 1998;20:97-105. https://doi.org/10.1002/ (SICI)1097-0347(199803)20:2<97::AID-HED1>3.0.CO;2-Y

66 Safi AF, Behn L, Rothamel D, et al. Therapy of sinonasal malignancies invading the orbit-orbital exenteration versus preservation of the orbit plus radiotherapy. J Cranio-Maxillofacial Surg 2017;45:258261. https://doi.org/10.1016/j.jcms.2016.11.013

67 Paré A, Blanchard P, Rosellini S, et al. Outcomes of multimodal management for sinonasal squamous cell carcinoma. J CranioMaxillofacial Surg 2017;45:1124-1132. https://doi.org/10.1016/j. jcms.2017.05.006

68 Vartanian JG, Toledo RN, Bueno T, et al. Orbital exenteration for sinonasal malignancies: indications, rehabilitation and oncologic outcomes. Curr Opin Otolaryngol Head Neck Surg 2018;26:122-126. https://doi.org/10.1097/MOO.0000000000000441

69 Neel GS, Nagel TH, Hoxworth JM, et al. Management of orbital involvement in sinonasal and ventral skull base malignancies. Otolaryngol Clin North Am 2017;50:347-364. https://doi.org/10.1016/j. otc.2016.12.010

70 Iannetti G, Valentini V, Rinna C, et al. Ethmoido-orbital tumours: our experience. J Craniofac Surg 2005;16:1085-1091. https://doi. org/10.1097/01.SCS.0000164332.81428.BA

71 Christianson B, Perez C, Harrow B, et al. Management of the orbit during endoscopic sinonasal tumour surgery. Int Forum Allergy Rhinol 2015;5:967-973. https://doi.org/10.1002/alr.21563

72 Turri-Zanoni M, Lambertoni A, Margherini S, et al. Multidisciplinary treatment algorithm for the management of sinonasal cancers with orbital invasion: a retrospective study. Head Neck 2019; 41:2777-2788. https://doi.org/10.1002/hed.25759

73 Shi J, Tu Y, Wu W. Combined external, endoscopic, endonasalassisted en bloc resection of malignant tumours from the lacrimal 
drainage system. J Craniofac Surg 2018;29:1855-1858. https://doi. org/10.1097/SCS.0000000000004655

74 Fontes ÉB, Wady A, Felippu D, et al. Surgical reconstruction technique of medial rectus muscle after endoscopic sinus surgery iatrogenic rupture - report of three cases. Rhinology Online 2020;3:167173. https://doi.org/10.4193/RHINOL/20.066

75 Sugawara T, Aoyagi M, Ogishima T, et al. Extended orbital exenteration for sinonasal malignancy with orbital apex extension: surgical technique and clinical analysis. J Neurosurg 2015;123:52-58. https:// doi.org/10.3171/2014.9.JNS141256

76 Mattavelli D, Schreiber A, Ferrari M, et al. Three-layer reconstruction with iliotibial tract after endoscopic resection of sinonasal tumours. World Neurosurg 2017;101:486-492. https://doi.org/10.1016/j. wneu.2017.02.066

77 Mattavelli D, Schreiber A, Villaret AB, et al. Complications and donor site morbidity of 3-layer reconstruction with iliotibial tract of the anterior skull base: retrospective analysis of 186 patients. Head Neck 2018;40:63-69. https://doi.org/10.1002/hed.24931

78 Bozkurt G, Leone F, Arosio AD, et al. Septal flip flap for anterior skull base reconstruction after endoscopic transnasal craniectomy: long-term outcomes. World Neurosurg 2019;128:e409-e416. https:// doi.org/10.1016/j.wneu.2019.04.166

79 Safavi-Abbasi S, Komune N, Archer JB, et al. Surgical anatomy and utility of pedicled vascularized tissue flaps for multilayered repair of skull base defects. J Neurosurg 2016;125:419-430. https://doi. org/10.3171/2015.5.JNS15529

80 Ferrari M, Vural A, Schreiber A, et al. Side-door temporoparietal fascia flap: a novel strategy for anterior skull base reconstruction. World Neurosurg 2019;126:e360-e370. https://doi.org/10.1016/j. wneu.2019.02.056

${ }^{81}$ Fortes FSG, Carrau RL, Snyderman CH, et al. Transpterygoid transposition of a temporoparietal fascia flap: a new method for skull base reconstruction after endoscopic expanded endonasal approaches. Laryngoscope 2007;117:970-976. https://doi.org/10.1097/ MLG.0b013e3180471482

82 Macía G, Picón M, Nuñez J, et al. The use of free flaps in skull base reconstruction. Int J Oral Maxillofac Surg 2016;45:158-162. https:// doi.org/10.1016/j.ijom.2015.09.001

${ }_{83}$ Gil Z, Abergel A, Leider-Trejo L, et al. A comprehensive algorithm for anterior skull base reconstruction after oncological resections. Skull Base 2007;17:25-37. https://doi.org/10.1055/s-2006-959333

${ }_{84}$ Herr MW, Lin DT. Microvascular free flaps in skull base reconstruction. Adv Otorhinolaryngol 2013;74:81-91. https://doi. org $/ 10.1159 / 000342283$

85 Neligan PC, Mulholland S, Irish J, et al. Flap selection in cranial base reconstruction. Plast Reconstr Surg 1996;98:1159-1168. https://doi. org/10.1097/00006534-199612000-00005

86 Reyes C, Solares CA, Fritz MA, et al. Fascia lata free flap anastomosed to the superior trochlear system for reconstruction of the anterior skull base. J Neurol Surgery Part B Skull Base 2017;78:393-398. https://doi.org/10.1055/s-0037-1602245

${ }_{87}$ Nouraei SAR, Ismail Y, Gerber CJ, et al. Long-term outcome of skull base surgery with microvascular reconstruction for malignant disease. Plast Reconstr Surg 2006;118:1151-1158. https://doi.org/10.1097/01. prs.0000236895.28858.4a

88 Lim X, Rajagopal R, Silva P, et al. A systematic review on outcomes of anterior skull base reconstruction. J Plast Reconstr Aesthetic Surg 2020;73:1940-1950. https://doi.org/10.1016/j.bjps.2020.05.044

89 Paprottka FJ, Krezdorn N, Ipaktchi R, et al. Plastic reconstructive surgery techniques for defect coverage of extended skull base defects. J Plast Reconstr Aesthetic Surg 2016;69:1266-1274. https://doi. org/10.1016/j.bjps.2016.06.008

90 Swendseid BP, Roden DF, Vimawala S, et al. Virtual surgical planning in subscapular system free flap reconstruction of midface defects. Oral Oncol 2020;101:104508. https://doi.org/10.1016/j. oraloncology.2019.104508

91 Spillinger A, Park K, Shenouda K, et al. Endoscopic management of postradiation skull base osteoradionecrosis. Int Forum Allergy Rhinol 2020;10:1329-1333. https://doi.org/10.1002/alr.22715

92 Habib A, Hanasono MM, DeMonte F, et al. Surgical management of skull base osteoradionecrosis in the cancer population - Treatment outcomes and predictors of recurrence: a case series. Oper Neurosurg 2020;19:364-374. https://doi.org/10.1093/ons/opaa082

93 Leonetti JP, Weishaar JR, Gannon D, et al. Osteoradionecrosis of the skull base. J Neurooncol 2020;150:477-482. https://doi.org/10.1007/ s11060-020-03462-3

94 Wang EW, Gardner PA, Zanation AM. International consensus statement on endoscopic skull-base surgery: executive summary. Int Forum Allergy Rhinol 2019;9:S127-S144. https://doi.org/10.1002/alr.22327

95 Del Carmen A, Romero B, Gangadharan JL, et al. Managing arterial injury in endoscopic skull base surgery: case series and review of the literature. Oper Neurosurg 2017;13:138-149. https://doi.org/10.1227/ NEU.0000000000001180

96 Nwosu OI, Rubel KE, Alwani MM, et al. Use of adenosine to facilitate localization and repair of internal carotid artery injury during skull base surgery: a case report and literature review. Ann Otol Rhinol Laryngol 2021;130:532-536. https://doi.org/10.1177/0003489420956373

97 Giorgianni A, Agosti E, Terrana A, et al. Emergency endovascular treatment of cavernous internal carotid artery acute bleeding with flow diverter stent: a single-center experience. Acta Neurochir (Wien) 2020 Aug 18. https://doi.org/10.1007/s00701-020-04517-0. Online ahead of print.

98 Lum SG, Gendeh BS, Husain S, et al. Internal carotid artery injury during endonasal sinus surgery: Our experience and review of the literature. Acta Otorhinolaryngol Ital 2019;39:130-136. https://doi. org/10.14639/0392-100X-1312

99 Wang CM, Guan ZY, Wang QC, et al. The effect of depth of anesthesia on hemodynamic changes induced by therapeutic compression of the trigeminal ganglion. J Neurosurg Anesthesiol 2020;32:344-348. https://doi.org/10.1097/ANA.0000000000000612

${ }^{100}$ Sharma SB, Janakiram TN, Baxi H, et al. Trigeminocardiac reflex during endoscopic juvenile nasopharyngeal angiofibroma surgery: an appraisal. Eur Arch Oto-Rhino-Laryngology 2017;274:2779-2784. https://doi.org/10.1007/s00405-017-4521-z 